\title{
High Ductile Behavior of a Polyethylene Fiber-Reinforced One-Part Geopolymer Composite: A Micromechanics-based Investigation
}

\author{
Behzad Nematollahi* ${ }^{1}$, Jay Sanjayan ${ }^{1}$, Jishen Qiu ${ }^{2}$, and En-Hua Yang ${ }^{2}$
}

${ }^{1}$ Center for Sustainable Infrastructure, School of Engineering, Faculty of Science, Engineering and Technology, Swinburne University of Technology, Melbourne, Victoria,

\section{Australia}

${ }^{2}$ School of Civil and Environmental Engineering, Nanyang Technological University, Singapore 639798, Singapore

*Corresponding author: Behzad Nematollahi

Phone no.: +61452593912; E-mail: bnematollahi@ swin.edu.au

Postal Address: Swinburne University of Technology, Mail 38, PO Box 218, FSET,

Hawthorn, VIC 3122, Australia 


\begin{abstract}
:
This study investigates the tensile performance a one-part strain hardening geopolymer composite (SHGC) reinforced by ultra-high-molecular-weight polyethylene (PE) fibers. The developed composite as a "dry mix" uses a small amount of solid activator rather than large quantities of commonly used alkaline solutions and eliminates the necessity for heat curing. The quantitative influences of curing condition (heat and ambient temperature curing) and type of fiber (poly vinyl alcohol (PVA) and PE fibers) on the macroscale properties of the matrix and composite including workability, density, compressive strength, and uniaxial tensile performance were evaluated. A micromechanics-based investigation was performed to explain the experimentally observed macroscopic high tensile ductility of the developed onepart PE-SHGCs. The investigation involved determination of the matrix fracture properties and the fiber-matrix interface properties using fracture toughness tests and single-fiber pullout tests, respectively. The fiber-bridging constitutive law of the composites was computed via a micromechanics-based model to link the material microstructures to macroscopic composite tensile performance. The results indicated that the ambient temperature curing increased the compressive and tensile strengths, but reduced the tensile ductility of the one-part PE-SHGCs. The one-part PE-SHGCs exhibited lower compressive and tensile strengths, but higher tensile ductility compared to the one-part PVA-SHGC.
\end{abstract}

Keywords: Strain hardening composite; Polyethylene fiber; High ductility; One-part geopolymer; Solid activator; Fiber-matrix interface.

\title{
1. Introduction
}

Nowadays, sustainability and concern for environmental impacts are becoming major considerations in construction industry, in particular the $\mathrm{CO}_{2}$ emissions and embodied energy of cement and concrete. Therefore, the investigation on high-performance and/or 
environmentally sustainable alternatives to ordinary Portland cement (OPC) is a rapidly advancing field of research area. Geopolymer is a cement-less and sustainable alternative binder to OPC, which has been increasingly studied over the past decades. It can be manufactured at ambient or elevated temperature by alkali activation of industrial by-products such as fly ash and slag. It has been reported that production of fly ash-based geopolymer requires $60 \%$ less energy and emits $80 \%$ less $\mathrm{CO}_{2}$ as compared to the manufacture of OPC $[1,2]$.

Previous studies revealed that fly ash-based geopolymer has good resistance to acid, sulfate and fire, negligible drying shrinkage, high compressive strength, good bond with steel bars and low creep [3-5]. It has also been demonstrated that the performance of structural members (e.g. beams and columns) made of geopolymer was comparable to that of conventional OPCconcrete members [6]. Although some studies have been conducted on fiber-reinforced geopolymer composites [7-10], these studies are yet far limited as compared to conventional fiber-reinforced cementitious composites.

The feasibility of developing ductile fiber-reinforced geopolymer composite (DFRGC) and fiber-reinforced strain-hardening geopolymer composite (SHGC) have been recently demonstrated by complete replacement of the OPC binder with fly ash-based geopolymer [11,12]. The developed DFRGC exhibited strong deflection-hardening behavior with high modulus of rupture of up to $11.5 \mathrm{MPa}$ and very high deflection capacity of up to $40 \mathrm{~mm}$ [11]. The developed SHGC demonstrated high tensile strain capacity of up to $4.3 \%$ with low to moderate compressive and tensile strengths of up to 27.6 MPa and 3.4 MPa, respectively [12]. The authors of this paper conducted a series of studies to systematically improve the mechanical properties (in particular compressive and tensile strengths) of the developed SHGC by optimizing the curing condition, type of activator and mix proportion [13-16]. The resulting fly ash-based SHGC developed by the authors demonstrated significantly improved 
compressive and tensile strengths of up to $63.7 \mathrm{MPa}$ and 5.0 $\mathrm{MPa}$, respectively, while material sustainability assessment results indicated that the resulting fly ash-based SHGC has significantly lower environmental footprints (52\% less carbon emissions and $17 \%$ less energy consumption) as compared to typical strain hardening cementitious composite (SHCC) [16].

However, the use of user-hostile alkaline solutions to manufacture the fly ash-based SHGC matrix and the necessity for heat curing are apparently the main two obstacles, which hinder the widespread application of the developed fly ash-based SHGC as a sustainable alternative to typical SHCC. In commercial and mass production of the SHGCs, handling large quantities of corrosive alkaline solutions might be challenging. In addition, the necessity for the heat curing could also limit the in-situ application of the developed SHGC. Recently, the authors of this paper succeeded to overcome the aforementioned two main obstacles by developing an ambient temperature cured one-part SHGC [17]. The developed geopolymer composite as a "dry-mix" uses a small amount of solid activators rather than large quantities of corrosive alkaline solution and eliminates the necessity for the heat curing, which in turn considerably enhances the commercial feasibility and widespread application of the SHGCs [17].

The aforementioned studies [13-17] clearly demonstrated that SHGCs reinforced by poly vinyl alcohol (PVA) fibers (PVA-SHGCs) can be successfully manufactured with comparable or superior properties to PVA-SHCCs. However, the behavior of the SHGCs reinforced by other types of fibers (e.g. polypropylene and polyethylene fibers) has received less attention. Therefore, in this study a detailed micromechanics-based investigation is performed to gain an in-depth understanding of the tensile performance of the one-part SHGC reinforced by ultra-high-molecular-weight polyethylene (UHMWPE, henceforth referred to as PE) fibers. In this regard, three mixtures with two curing conditions, namely heat and ambient temperature curing, and two types of fiber, viz. hydrophilic PVA fiber and hydrophobic PE fiber, were 
prepared. A series of experiments including matrix workability, density, compression, and uniaxial tension tests were conducted to determine the quantitative influences of curing condition and type of fiber on the macroscale properties of the matrix and composite. Matrix fracture toughness tests and single-fiber pullout tests were also performed to determine the matrix fracture properties and the microscale fiber-matrix interface properties, respectively. The fiber-bridging constitutive law $\sigma(\delta)$ of the developed one-part SHGCs was computed using a micromechanics-based model to elucidate the experimentally observed macroscopic tensile performance of the composites.

\section{Experimental Procedures}

\subsection{Materials and mix proportion}

In a previous study conducted by the authors, a suitable ambient temperature cured one-part geopolymer matrix was developed to be used for the manufacture of the one-part SHGCs [18]. The results indicated that the ambient temperature cured one-part geopolymer matrix composed of fly ash $(50 \% \mathrm{w} / \mathrm{w})$, slag $(50 \% \mathrm{w} / \mathrm{w})$, anhydrous sodium metasilicate powder $(0.08 \% \mathrm{w} / \mathrm{w})$ and water $(0.35 \mathrm{w} / \mathrm{w})$ exhibited desirable mechanical properties, moderate setting time and adequate rheology for uniform fiber dispersion [18]. Table 1 presents the one-part SHGC mix proportions investigated in this study. As can be seen, three appropriate mix proportions were designed to evaluate the influence of curing condition and type of fiber on the matrix, fiber-matrix interface and composite properties of the one-part SHGCs.

The low calcium (Class F) fly ash and slag used in this study were supplied from Gladstone power station in Queensland, Australia and Independent Cement and Lime Pty Ltd, Australia, respectively. The chemical composition and loss on ignition (LOI) of the fly ash and slag determined by X-ray Fluorescence (XRF) are presented in Table 2. The total percentages do not sum up to $100 \%$ because of rounding errors. The X-ray diffraction (XRD) patterns of the 
fly ash and slag are presented in Figure 1. It should be noted that the amorphous contents of considered as unreacted components, which act as filler in the one-part geopolymer matrix [17]. Therefore, unlike typical SHCC mix 45 (M45) mixture [19], micro-silica sand was not used in the one-part SHGC mixtures investigated in this study. The anhydrous sodium metasilicate powder used in this study has a chemical composition of 51 wt. $\% \mathrm{Na}_{2} \mathrm{O}$ and 46 wt.\% $\mathrm{SiO}_{2}$ (balance $\mathrm{H}_{2} \mathrm{O}$ ). It was supplied by Redox, Australia. Properties of the PVA and PE fibers used in this study are presented in Table 3. The PVA and PE fibers were supplied by Kuraray Co. Ltd., Japan and Toyobo Co. Ltd., Japan, respectively.

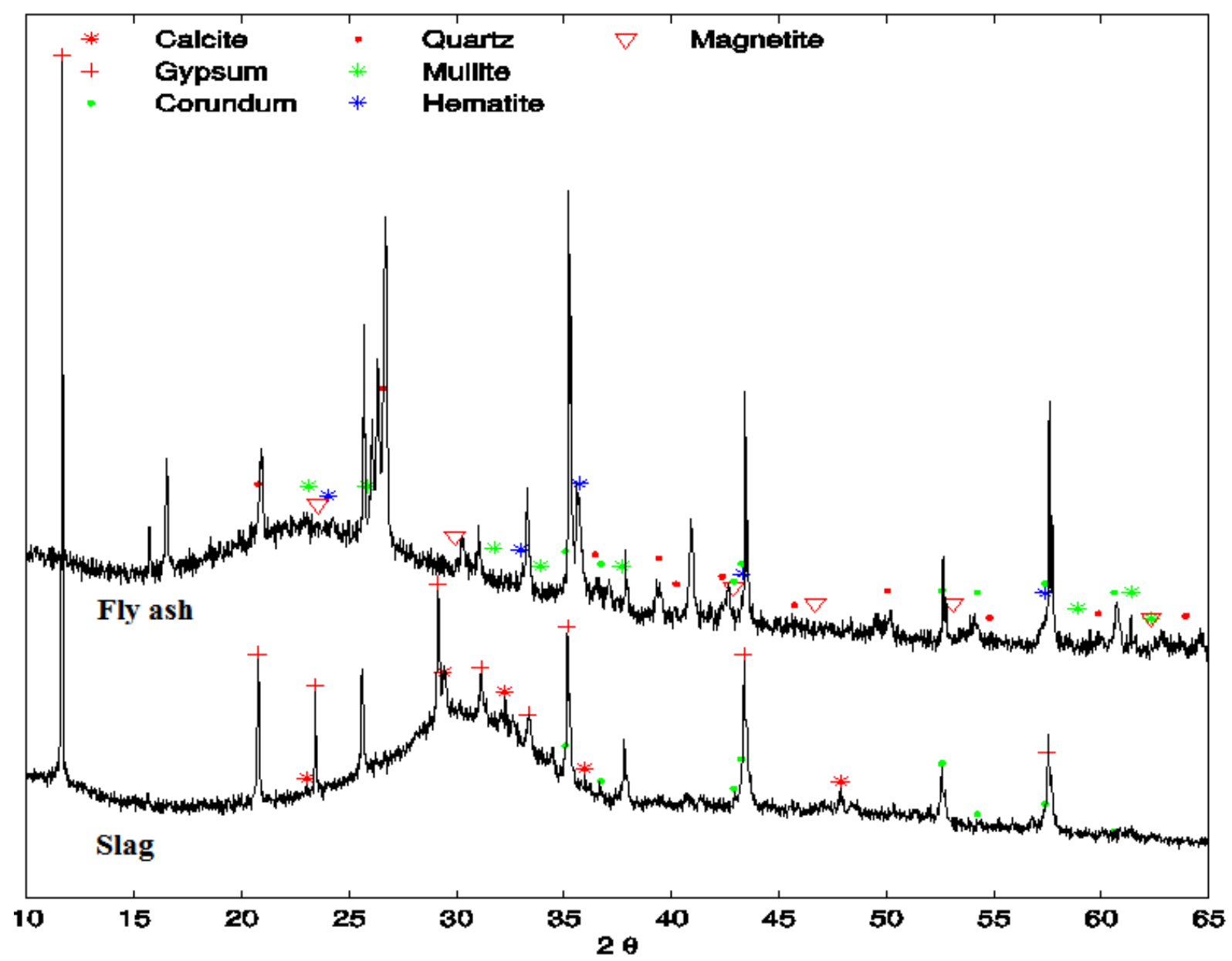

Figure 1: XRD patterns of the fly ash and slag

\subsection{Mixing, curing and testing of specimens}


To make the one-part geopolymer matrix, fly ash, slag and solid activator were added to a the mix and the mixing was continued for another eight minutes. After the matrix ingredients were thoroughly mixed to achieve a consistent fresh flowable state, the flowability of the geopolymer matrix (before addition of the fibers) was measured to ensure that the flowability was within the desired range for achieving good fiber dispersion. Finally, the fibers $(2 \% \mathrm{v} / \mathrm{v})$ were gradually added to ensure uniform fiber dispersion. The total mixing time for each mix was about 20 minutes. The fresh geopolymer matrix and composite were cast into different molds and compacted via a vibrating table.

For the ambient temperature curing, the specimens were cured in air at ambient temperature $\left(23^{\circ} \mathrm{C} \pm 3^{\circ} \mathrm{C}\right)$ for 24 hours. The hardened specimens were then demolded and cured in a water tank at a temperature of $23^{\circ} \mathrm{C} \pm 3^{\circ} \mathrm{C}$ for 27 days after de-molding. For the heat curing, the molds were sealed to avoid excessive loss of moisture and kept in an oven at a temperature of $60^{\circ} \mathrm{C}$ for 24 hours. Subsequently, the molds were taken out from the oven and left undisturbed to cool down. The specimens were then demolded and kept in the laboratory at ambient temperature $\left(23^{\circ} \mathrm{C} \pm 3^{\circ} \mathrm{C}\right)$ until the testing day. The ambient temperature cured specimens were tested 28 days after casting, while the heat cured specimens were tested 3 days after casting. It was reported that age does not have significant influence on strength of geopolymers when the heat curing period is ended $[5,20]$.

Mini slump test was performed to measure the workability of the one-part geopolymer matrix. Details of the mini-slump test is given in Nematollahi and Sanjayan [21]. The compressive strength of each mix was measured in accordance with ASTM C109 [22]. In this regard, for each mix a minimum of six $50 \mathrm{~mm}$ cube specimens (three matrix specimens and three composite specimens) were prepared. The density of each mix was calculated by weighing the cube specimens at the testing day. Uniaxial tension tests were performed to characterize the 
tensile performance of the developed one-part SHGCs. For each mix, a minimum of three rectangular coupon specimens measuring $400 \mathrm{~mm} \times 75 \mathrm{~mm} \times 10 \mathrm{~mm}$ were prepared. All coupon specimens were tested in uniaxial tension under displacement control at the rate of $0.25 \mathrm{~mm} / \mathrm{min}$ over a gauge length of about $80 \mathrm{~mm}$. Further details of the uniaxial tension test is given in Nematollahi et al. [14].

Three-point bending tests on single edge notched beam specimens were conducted to determine the matrix fracture properties of the one-part geopolymer matrix comprising elastic modulus $\left(\mathrm{E}_{\mathrm{m}}\right)$, fracture toughness $\left(\mathrm{K}_{\mathrm{m}}\right)$ and crack tip toughness $\left(J_{\text {tip }}\right)$. For each mix, a minimum of four matrix prisms (without addition of the fibers) measuring of $60 \mathrm{~mm} \times 60$ $\mathrm{mm} \times 280 \mathrm{~mm}$ were prepared. The $\mathrm{E}_{\mathrm{m}}$ and $\mathrm{K}_{\mathrm{m}}$ of each mix were computed using effective crack model (ECM) developed by Karihaloo and Nallathambi [23]. Details of the three-point bending test and the formulas for calculating the $\mathrm{E}_{\mathrm{m}}$ and $\mathrm{K}_{\mathrm{m}}$ are given in Nematollahi et al. [14]. Single-fiber pullout tests were also performed to determine the fiber-matrix interface properties of each mix comprising chemical bond strength $\left(\mathrm{G}_{\mathrm{d}}\right)$, frictional bond strength $\left(\tau_{0}\right)$, and slip-hardening coefficient $(\beta)$. Details of the single-fiber pullout test and the procedure for calculation of interface parameters can be found in Redon et al. [24] and Nematollahi et al. [17].

\section{Results and Discussions}

\subsection{Workability, density and compressive strength}

The workability of the fresh one-part SHGC matrix is given in Table 4. It should be pointed out that the relative slump value reported in Table 4 is based on the mini-slump test without the 25 times tamping of the flow table. Visual observations revealed that the one-part SHGC matrix exhibited thixotropic properties. In other words, the fresh one-part SHGC matrix 
exhibited adequate workability to guarantee uniform fiber dispersion as being mixed and vibrated, thanks to its thixotropic properties.

The average density of each mix is also given in Table 4. As can be seen, the curing condition and type of fiber did not have any significant effect on the density of the developed one-part SHGCs and their corresponding one-part SHGC matrices. The density of the developed onepart SHGCs, regardless of the curing condition and type of fiber, was relatively lower than that of the corresponding one-part SHGC matrices. This could be due to a fiber-induced air entrapping effect, leading to a composite with higher porosity than the matrix material alone [25]. The density of the developed one-part SHGCs was in the range of $1837 \mathrm{~kg} / \mathrm{m}^{3}$ to 1849 $\mathrm{kg} / \mathrm{m}^{3}$, which is $23 \%$ less than that of a normal weight concrete with a density of $2400 \mathrm{~kg} / \mathrm{m}^{3}$ and meet the density requirement for lightweight concrete (below $1850 \mathrm{~kg} / \mathrm{m}^{3}$ ) [26]. It should be pointed out that the density of the developed one-part SHGCs is $11-12 \%$ less than that of typical SHCC M45 (2077 kg/m³) [19]. This may be attributed to the lower specific density of fly ash $\left(2.45 \mathrm{~g} / \mathrm{cm}^{3}\right)$ and slag $\left(2.85 \mathrm{~g} / \mathrm{cm}^{3}\right)$ than that of cement $\left(3.15 \mathrm{~g} / \mathrm{cm}^{3}\right)$ and exclusion of micro-silica sand from the one-part SHGC mixtures.

The average compressive strength of each mix is also given in Table 4. As can be seen, the compressive strength of the ambient temperature cured one-part PE-SHGC-A and its corresponding matrix was higher than that of the counterpart heat cured matrix and composite. With regards to the type of fiber, the compressive strengths of the one-part PESHGCs, regardless of the curing condition, were 9-24\% lower than that of the corresponding one-part SHGC matrices. As mentioned earlier, this could be attributed to the higher porosity of the composite specimens than that of the matrix specimens, due to the fiber induced damage effect [25]. Nevertheless, the compressive strength of the ambient temperature cured one-part PVA-SHGC-A was comparable to that of the ambient temperature cured one-part SHGC matrix. In addition, the compressive strength of the ambient temperature cured one- 
part PVA-SHGC-A was slightly higher than that of the ambient temperature cured one-part PE-SHGC-A. This could be due to the lower aspect ratio of the PVA fibers than that of the PE fibers, which suggests that the PVA fibers may induce less fiber damage effect (air entrapping effect) in the composite compared to the PE fibers.

The compressive strength of the developed one-part SHGCs ranged from 33.9 MPa to 48.7 $\mathrm{MPa}$, which is well above the compressive strength requirement of $17 \mathrm{MPa}$ for structural lightweight concrete [26]. Among all one-part SHGCs, the ambient temperature cured onepart PVA-SHGC-A exhibited the highest compressive strength, comparable to SHCC M45 (52.6 MPa) [19]. However, unlike SHCC M45, the ambient temperature cured one-part PVASHGC-A contains no cement, and therefore it has significantly lower environmental footprints compared to the SHCC M45, in which its cement content is still 1.5 times that of normal concrete [19].

\subsection{Matrix fracture properties}

Fracture properties of the developed one-part SHGC matrices (without addition of the fibers) are summarized in Table 5. It should be noted that the $\mathrm{E}_{\mathrm{m}}$ values reported in Table 5 were not experimentally measured using cylindrical specimens in compression, instead they were derived based on ECM [23] from the linear part of the load-deflection curve of the notched beam specimen in three-point bending tests. Therefore, they should only be considered as relative values enabling us to compare the elastic modulus of the one-part SHGC matrices. As can be seen, the elastic modulus of the ambient temperature cured one-part SHGC matrix was slightly higher than that of the heat cured matrix. This is consistent with the results presented in Table 4, where the compressive strength of the ambient temperature cured one-part SHGC matrix was marginally higher than that of the heat cured matrix. 
As can be seen in Table 5, the fracture toughness of the ambient temperature cured one-part propagation in the ambient temperature cured one-part SHGC matrix is likely to be more tortuous; thereby, consumes more energy than that of the heat cured matrix. This trend is confirmed by visual observations of the fracture surface of the specimens. Fracture toughness is a measure of stress concentration in front of the crack tip when the crack starts to propagate [27]. There are several studies on fracture properties of conventional OPC concrete. For instance, Golewski and Sadowski [28] studied the effect of addition of fly ash on mode II fracture toughness and internal microstructure of OPC concrete. In contrast, studies on fracture properties of geopolymer materials are still far limited [29]. The fracture toughness of concrete is mainly affected by the size, texture and angularity of the coarse aggregates, as well as the microstructure of the paste [29]. Thereby, it can be inferred that the main reason for the difference in the fracture toughness of the one-part SHGC matrices lies in their different geopolymer microstructures originated from their different curing conditions, because all other parameters, except the curing condition, were kept constant for both matrices. According to Li et al. [30], the $J_{t i p}$ can be calculated from the following equation:

$J_{\text {tip }}=\frac{K_{m}^{2}}{E_{m}}$

As can be seen in Table 5, the $J_{\text {tip }}$ of the ambient temperature cured one-part SHGC matrix was higher than that of the heat cured matrix, which corresponds to its higher $\mathrm{K}_{\mathrm{m}}$. It is thereby concluded that the ambient temperature curing reduces the brittleness of the one-part SHGC matrix.

\subsection{Fiber-matrix interface properties}


The fiber-matrix interface properties of each mix are summarized in Table 6. With regards to effect of the curing condition on the interface properties, both $\tau_{0}$ and $\beta$ of the ambient temperature cured one-part PE-SHGC-A were higher than those of the counterpart heat cured composite. This could be due to the higher matrix fracture toughness of the ambient temperature cured one-part SHGC matrix. Lang et al. [31] reported that there is a positive correlation between fracture surface roughness and fracture toughness. As fracture toughness increases, fracture surface roughness increases. Therefore, it can be inferred that in the ambient temperature cured one-part PE-SHGC-A the fracture surface roughness in the fibermatrix interfacial zone is higher, due to its higher matrix toughness, as shown in Table 5. This increases the contact surface between the fiber and the matrix in the interfacial zone during the fiber slippage, and thereby leading to the higher frictional bond strength in the ambient temperature cured one-part PE-SHGC-A. Similarly, due to the higher matrix fracture toughness, and thereby rougher fracture surface in the fiber-matrix interfacial zone in the ambient temperature cured one-part PE-SHGC-A, the fiber is more likely to be abraded during fiber slippage and a jamming effect is more likely to occur, leading to the relatively higher $\beta$ value of the ambient temperature cured one-part PE-SHGC-A.

With regards to effect of the type of fiber on the interface properties, unlike PE fiber, as expected the PVA fiber due to its hydrophilic nature exhibited a chemical bond with the ambient temperature cured one-part SHGC matrix [32]. In addition, the $\tau_{0}$ and $\beta$ of the ambient temperature cured one-part PVA-SHGC-A were considerably higher than those of the counterpart composite reinforced by the PE fibers. The higher frictional bond strength of the PVA fibers with the surrounding one-part SHGC matrix is also attributed to its hydrophilic characteristics [32]. The significantly higher $\beta$ of the PVA fibers is due to its lower elastic modulus [24]. As shown in Table 3, the elastic modulus of the PVA fibers is 3 times less than that of the PE fibers. According to Redon et al. [24], the lower the fiber 
hardness than that of the surrounding matrix, the higher the possibility of fiber damage and jamming effect in the slippage regime, resulting in higher $\beta$ value.

\subsection{Uniaxial tensile performance}

Tensile stress-strain responses of the developed one-part SHGCs are presented in Figures 2 to 4. As can be seen, all one-part SHGCs, regardless of the curing condition and type of fiber, exhibited strong strain hardening behavior. The uniaxial tension test results including the average measured ultimate tensile strength $\left(\sigma_{c u}\right)$ and tensile strain capacity $\left(\varepsilon_{c u}\right)$ and the estimated first-crack strength $\left(\sigma_{f c}\right)$ are summarized in Table 7 . As can be seen, the developed one-part PE-SHGCs exhibited moderate to high ultimate tensile strength in the range of 3.3-4.2 MPa and very high tensile ductility in the range of $4.9-5.5 \%$, whereas the ambient temperature cured one-part PVA-SHGC-A exhibited high ultimate tensile strength and very high tensile ductility of up to $4.6 \mathrm{MPa}$ and $4.2 \%$, respectively.

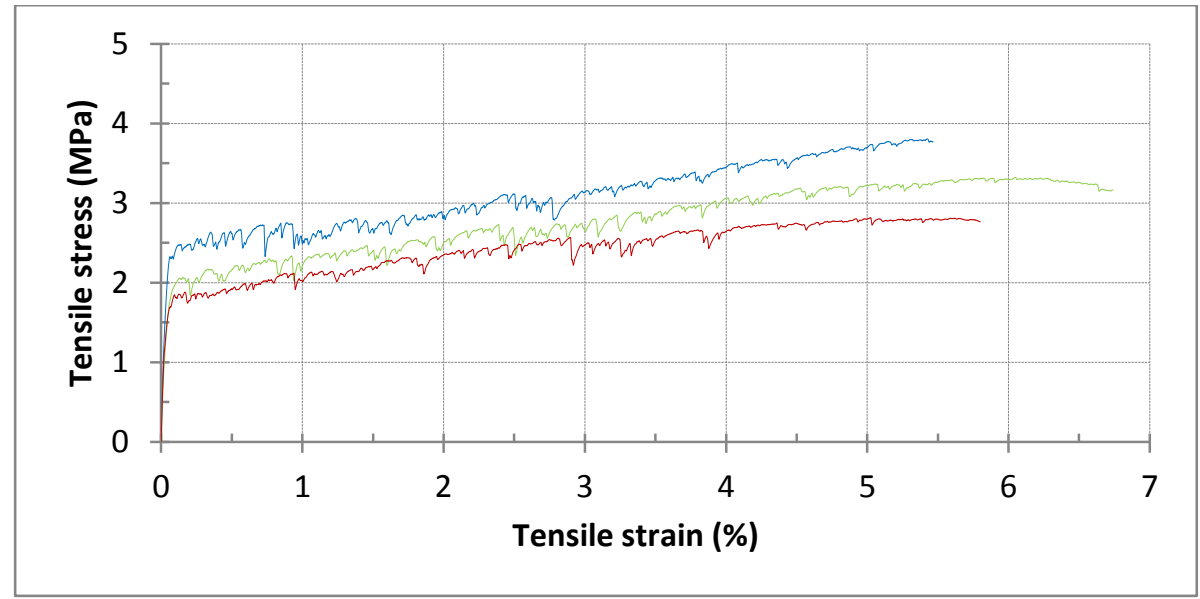

Figure 2: Tensile stress-strain responses of heat cured one-part PE-SHGC-H 


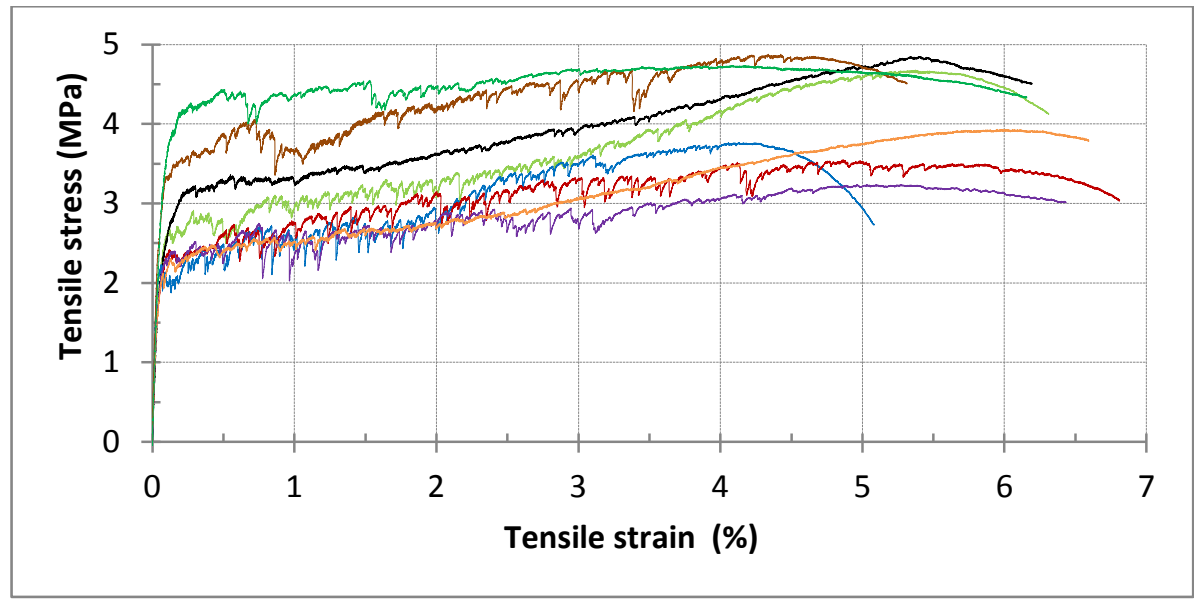

Figure 3: Tensile stress-strain responses of ambient temperature cured one-part PE-SHGC-A

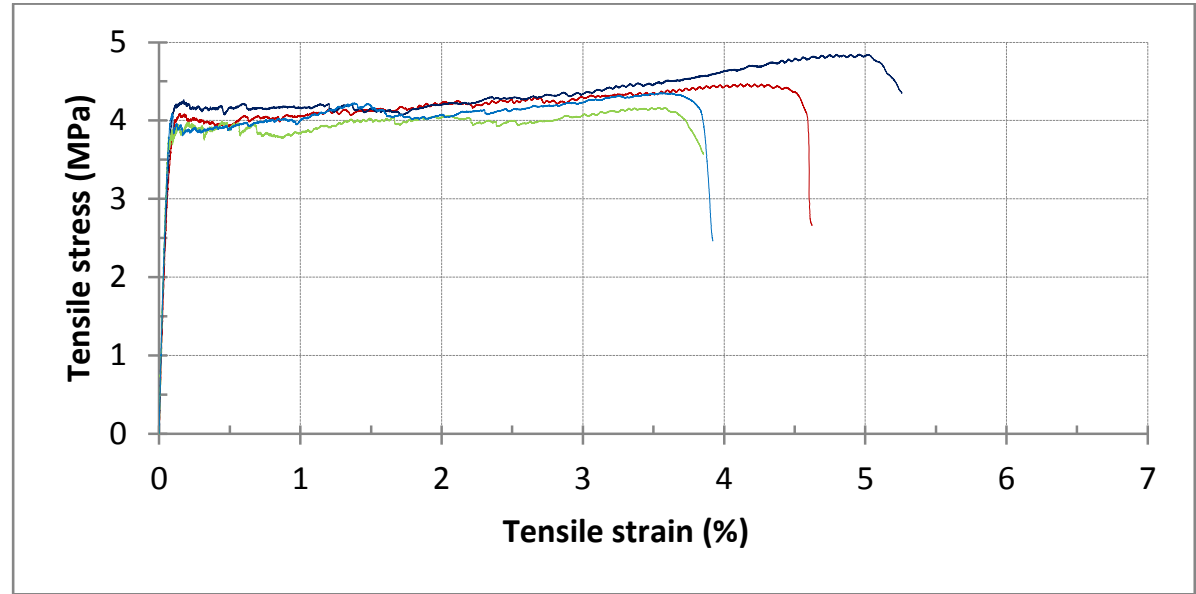

Figure 4: Tensile stress-strain responses of ambient temperature cured one-part PVA-SHGCA

In terms of the effect of the curing condition on the tensile performance of the one-part PESHGCs, as can be seen in Table 7, the first-crack strength and the ultimate tensile strength of the ambient temperature cured one-part PE-SHGC-A were 33\% and 27\% higher, respectively than those of the counterpart heat cured composite. The higher first-crack strength of the ambient temperature cured one-part PE-SHGC-A corresponds to its higher matrix fracture toughness, as shown in Table 5 [33]. The higher ultimate tensile strength of the ambient temperature cured one-part PE-SHGC-A is attributed to the fiber-matrix interface properties. In other words as shown in Table 6 , the $\tau_{0}$ and $\beta$ of the ambient temperature cured one-part PE-SHGC-A were higher than those of the counterpart heat cured composite, resulting in its higher fiber bridging strength $[14,15]$. 
In contrast, the tensile strain capacity of the ambient temperature cured one-part PE-SHGC-A tensile ductility of the heat cured and ambient temperature cured one-part PE-SHGCs can be described in terms of the two pseudo strain hardening (PSH) performance indices recommended by Kanda and Li [34], which could be calculated based on the micromechanics modeling of fiber-bridging behavior. Adequate margins between maximum fiber bridging stress $\left(\sigma_{0}\right)$ and tensile first cracking strength $\left(\sigma_{f c}\right)$, as well as complementary energy $\left(J_{b}^{\prime}\right)$ and $J_{\text {tip }}$ are desirable to have robust PSH behavior in short fiber reinforced brittle matrix composites. This is because of random distribution of fibers and pre-existing flaw size in the composite [35]. Two PSH performance indices, namely PSH strength index $\left(\sigma_{0} / \sigma_{f c}\right)$ and PSH energy index $\left(J_{b}^{\prime} / J_{t i p}\right)$ were proposed by Kanda and Li [34] to be able to asses these margins quantitatively. Theoretically, both PSH performance indices must be greater than unity to achieve the PSH behavior in the composite. The higher the PSH performance indices, the greater the possibility of saturated multiple cracking and PSH behavior, which in turn results in higher tensile strain capacity of the composite.

In this study, the micromechanical model developed by Yang et al. [36] was used to compute the fiber-bridging constitutive law $\sigma(\delta)$ of the developed one-part SHGCs. The resulting PSH performance indices are presented in Figure 5. As can be seen, in all composites both PSH performance indices exceed unity, and hence it can be concluded that the necessary strength and energy-based conditions for the PSH behavior are satisfied. Therefore, all one-part SHGCs developed in this study exhibited strain hardening behavior. In addition, the PSH strength and energy indices of the heat cured one-part PE-SHGC-H were 5\% and $21 \%$, respectively higher than those of the counterpart ambient temperature cured composite. As a result, it is not surprising that the heat cured one-part PE-SHGC-H with higher PSH 
performance indices exhibited higher tensile strain capacity than that of the counterpart ambient temperature cured composite.

With regards to the effect of the type of fiber on the tensile performance of the one-part SHGCs, as shown in Table 7, the first-crack strength and the ultimate tensile strength of the ambient temperature cured one-part PVA-SHGC-A were $46 \%$ and $10 \%$ higher, respectively than those of the ambient temperature cured one-part PE-SHGC-A. The higher first-crack strength of the ambient temperature cured one-part PVA-SHGC-A is attributed to its higher fiber-matrix interface properties, especially the strong chemical bond of the PVA fibers with the one-part SHGC matrix, as shown in Table 6. In general, the first-crack strength of the composite is governed by the matrix properties, as well as fiber bridging properties, especially the chemical bond strength [37]. The higher ultimate tensile strength of the ambient temperature cured one-part PVA-SHGC-A is attributed to the significantly higher $\tau_{0}$ and $\beta$ of the PVA fibers as shown in Table 6, resulting in its higher fiber bridging strength $[14,15]$.

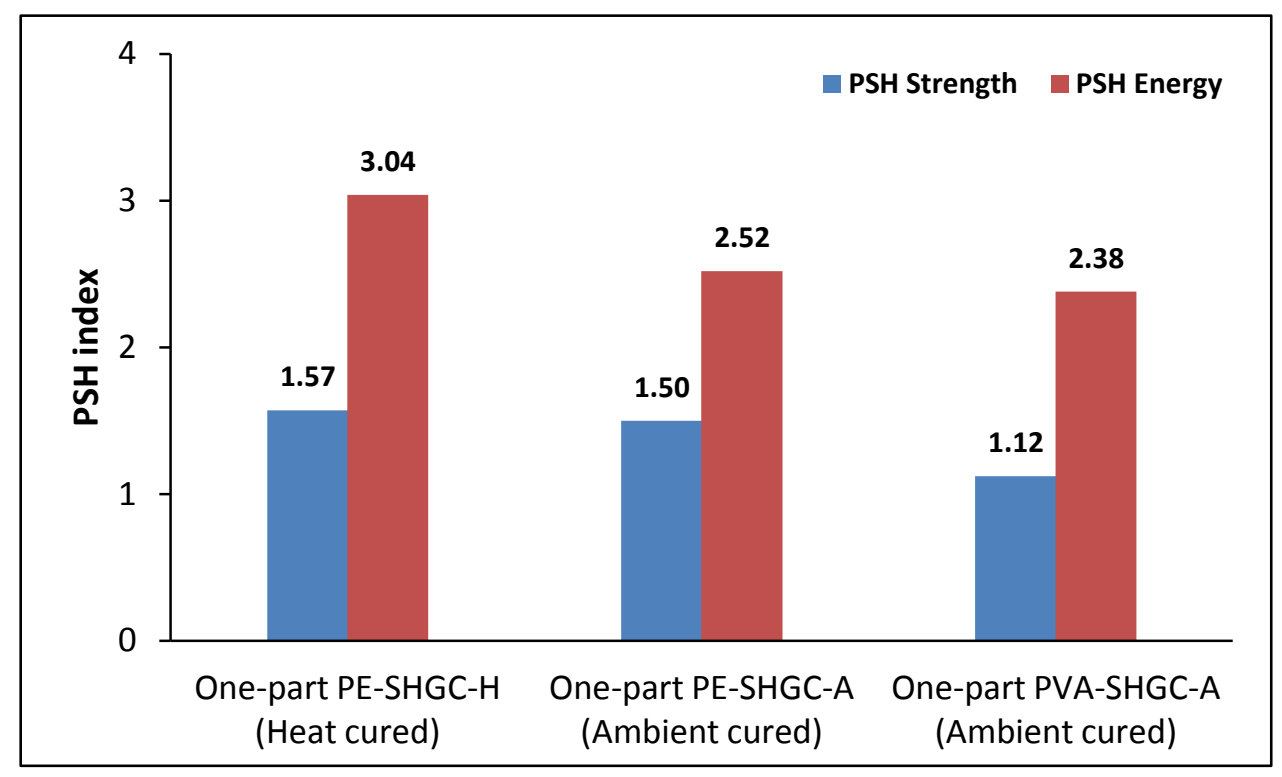

Figure 5: PSH indices of the developed one-part SHGCs

In contrast, the tensile strain capacity of the ambient temperature cured one-part PVA-SHGCA was $14 \%$ lower than that of the ambient temperature cured one-part PE-SHGC-A. Similar 
to the above discussion, the reasons for the lower tensile ductility of the ambient temperature cured one-part PVA-SHGC-A could also be described based on the two PSH performance indices. As can be seen in Figure 5, the PSH strength and energy indices of the ambient temperature cured one-part PVA-SHGC-A were $25 \%$ and $6 \%$, respectively lower than those of the ambient temperature cured one-part PE-SHGC-A. This can be attributed to the strong chemical bond and higher frictional bond and slip hardening coefficient of the PVA fiber with the ambient temperature cured SHGC matrix, as well as the lower strength of the PVA fiber, which result in lower complimentary energy of the composite. Therefore, the tensile strain capacity of the ambient temperature cured one-part PVA-SHGC-A was lower than that of the ambient temperature cured one-part PE-SHGC-A.

The crack pattern of each composite is presented in Figure 6. As can be seen, uniform crack distribution with similar spacing was observed in all developed one-part SHGCs, regardless of the curing condition and type of fiber. Saturated multiple cracking behavior (i.e. numerous micro cracks with very tight width) was observed on the surface of the coupon specimens, corresponding to the very high tensile strain capacity of the developed composites. It should be pointed out that the number of cracks formed during testing of the specimens was more than the number of visible cracks on the surface of the specimens after unloading, which illustrated in Figure 6. This is because many of the micro cracks formed during testing, completely closed when unloaded the specimens, which thereby made them hard to be detected on the specimen's surface after the test [14,33]. 


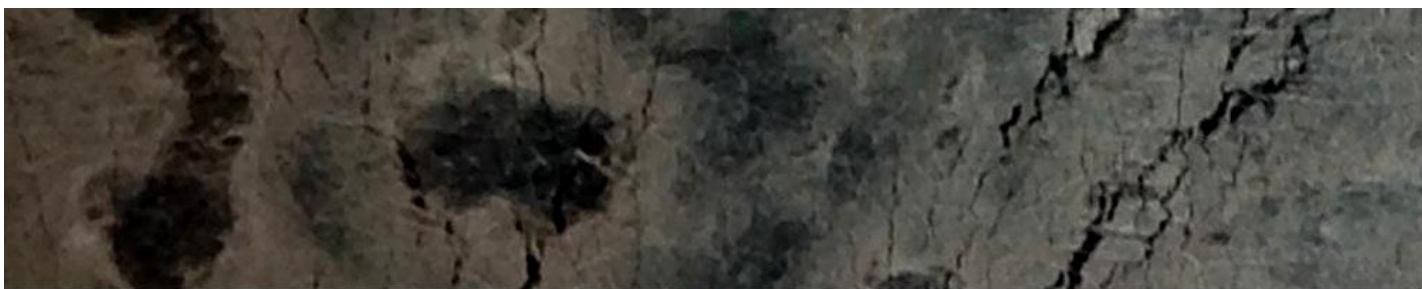

(a)

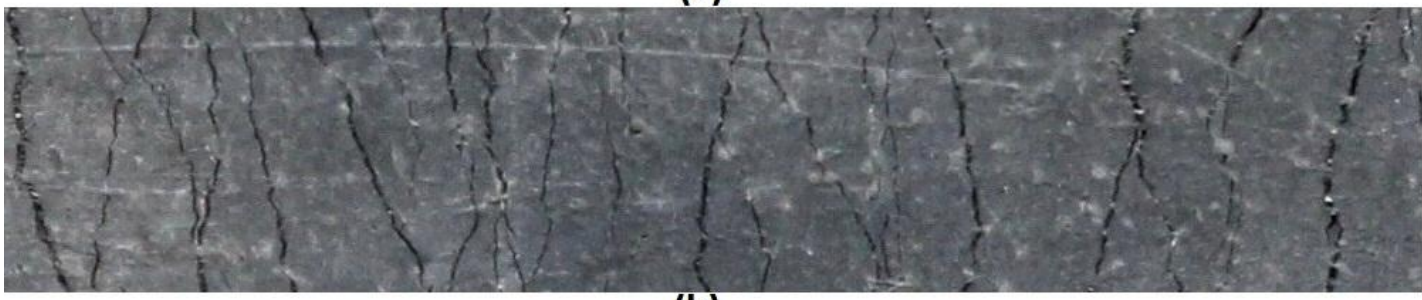

(b)

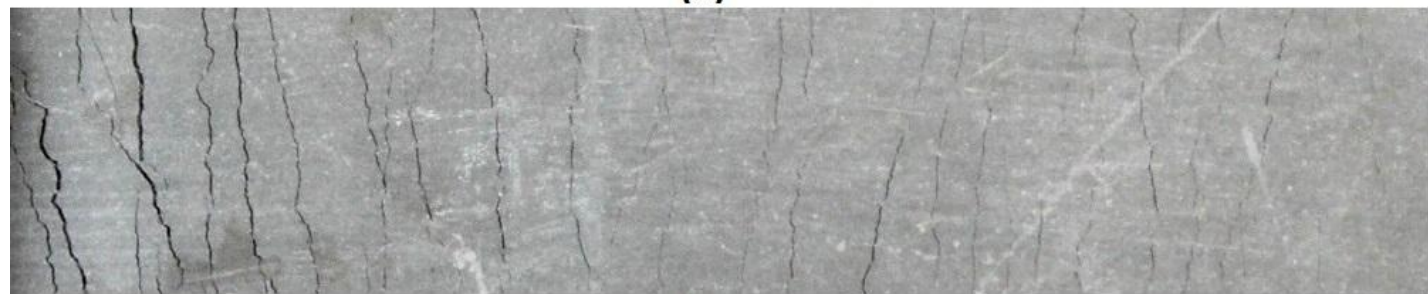

(c)

Figure 6: Typical multiple cracking pattern of (a) ambient temperature cured one-part PESHGC-A, (b) heat cured one-part PE-SHGC-H, and (c) ambient temperature cured one-part PVA-SHGC-A

\section{CONCLUSIONS}

A detailed micromechanics-based investigation was conducted in this study to fully explain the experimentally observed high ductile behavior of a one-part SHGC reinforced by high strength and high modulus PE fibers. The quantitative effects of curing condition and type of fiber on the matrix and fiber-matrix interface properties, along with their consequent quantitative influences on the macroscale properties of the developed one-part SHGCs were experimentally investigated. The crack bridging relation and the pseudo-strain hardening (PSH) performance indices of the composites were computed using the existing micromechanical model to elucidate the experimentally observed macroscopic tensile performance of the developed one-part SHGCs. The following conclusions are drawn:

1) The first-crack strength of the ambient temperature cured one-part PE-SHGC was considerably higher than that of the counterpart heat cured composite. This corresponds the 
higher fracture toughness of the ambient temperature cured one-part SHGC matrix. In addition, the ultimate tensile strength of the ambient temperature cured one-part PE-SHGC was also noticeably higher than that of the counterpart heat cured composite. This is attributed to the higher $\tau_{0}$ and $\beta$ of the PE fiber with the ambient temperature cured one-part SHGC matrix. In contrast, the tensile strain capacity of the heat cured one-part PE-SHGC was higher than that of the counterpart ambient temperature cured composite. This result is well consistent with the calculated PSH performance indices of the composites, where both PSH strength and energy indices of the heat cured one-part PE-SHGC were relatively higher, resulting in the higher tensile ductility of the heat cured composite.

2) The type of fiber had significant effects on the microscale fiber-matrix interface properties, and thereby on the macroscopic tensile performance of the composite. The first-crack strength of the ambient temperature cured one-part PVA-SHGC was significantly higher than that of the ambient temperature cured one-part PE-SHGC. This is due to the higher interface properties, especially the strong chemical bond $\left(\mathrm{G}_{\mathrm{d}}\right)$ of the PVA fiber with the one-part SHGC matrix. In addition, the ultimate tensile strength of the ambient temperature cured one-part PVA-SHGC was also higher. This is due to the significantly higher $\tau_{0}$ and $\beta$ of the PVA fiber with the one-part SHGC matrix, resulting in the higher fiber bridging strength of the composite. However, the tensile strain capacity of the ambient temperature cured one-part PVA-SHGC was lower than that of the ambient temperature cured one-part PE-SHGC. This result is also in good agreement with the computed PSH performance indices of the composites, where both PSH strength and energy indices of the ambient temperature cured one-part PVA-SHGC were relatively lower. This is attributed to the strong $\mathrm{G}_{\mathrm{d}}$ and higher $\tau_{0}$ and $\beta$ of the PVA fiber with the one-part SHGC matrix, along with the lower strength of the PVA fiber, which result in lower complimentary energy of the ambient temperature cured one-part PVA-SHGC. 
3) The ambient temperature curing condition increased the micro-scale fiber-matrix interface properties (frictional bond $\tau_{0}$ and slip hardening coefficient $\beta$ ) of the PE fiber with the onepart SHGC matrix. This is attributed to the higher fracture toughness of the ambient temperature cured one-part SHGC matrix, in which increases the roughness of the fracture surface in the fiber-matrix interfacial zone, and thereby increases the contact surface between the fiber and matrix in the interfacial zone during the fiber slippage.

4) The ambient temperature curing condition marginally increased the compressive strength, elastic modulus and fracture toughness of the one-part SHGC matrix. It is thereby concluded that ambient temperature curing condition reduces the brittleness of the one-part SHGC matrix.

\section{REFERENCES}

[1] Li, Z., Ding, Z., and Zhang, Y. (2004). "Development of sustainable cementitious materials". Paper presented at the Proceedings of the international workshop on sustainable development and concrete technology.

[2] Duxson, P., Provis, J.L., Lukey, G.C., and van Deventer, J.S.J. (2007). "The role of inorganic polymer technology in the development of 'green concrete"'. Cement and Concrete Research. 37(12):1590-7.

[3] Rangan, B.V. (2008). Fly Ash-Based Geopolymer Concrete. Research Report GC 4Faculty of Engineering, Curtin University of Technology, Perth, Australia.

[4] Sarker, P. K. (2009). "Analysis of geopolymer concrete columns". Materials and Structures, 42(6), 715- 724.

[5] Kong, D.L., and Sanjayan, J.G. (2010). "Effect of elevated temperatures on geopolymer paste, mortar and concrete". Cement and Concrete Research. 40(2), 334-9.

[6] Sumajouw, M.D.J., and Rangan, B.V. (2006). Low-Calcium Fly Ash-Based Geopolymer Concrete: Reinforced Beams and Columns. Research Report GC 3-Faculty of Engineering, Curtin University of Technology, Perth, Australia.

[7] Li, Z., Zhang, Y., and Zhou, X. (2005). "Short fiber reinforced geopolymer composites manufactured by extrusion". ASCE Journal of Materials in Civil Engineering, 17(6), 624-631. [8] Ng, T.S., Amin, A., and Foster, S.J. (2013). "The behavior of steel-fiber-reinforced geopolymer concrete beams in shear". Magazine of Concrete Research, 65(5), 308-318.

[9] Nematollahi B., Sanjayan J., Chai J.X.H. and Lu T.M. (2014). "Properties of Fresh and Hardened Glass Fiber Reinforced Fly Ash Based Geopolymer Concrete". Key Engineering Materials, 594, 629-633.

[10] Masi, G., Rickard, W. D., Bignozzi, M. C., and van Riessen, A. (2015). "The effect of organic and inorganic fibers on the mechanical and thermal properties of aluminate activated geopolymers". Composites Part B: Engineering, 76, 218-228. 
[11] Nematollahi, B., Sanjayan, J., and Shaikh, F.U.A. (2014). "Comparative Deflection Building Materials, 70, 54-64.

[12] Ohno, M., and Li, V.C. (2014). "A feasibility study of strain hardening fiber reinforced fly ash-based geopolymer composites". Construction and Building Materials, 57, 163-168.

[13] Nematollahi, B., Sanjayan, J., and Shaikh, F.A.U. (2015). "Strain Hardening Behavior of Engineered Geopolymer Composites: Effects of the Activator Combination". Journal of The Australian Ceramic Society, 51(1), 54 - 60

[14] Nematollahi, B., Sanjayan, J., and Ahmed Shaikh, F. (2015). "Tensile Strain Hardening Behavior of PVA Fiber-Reinforced Engineered Geopolymer Composite." ASCE Journal of Materials in Civil Engineering, 27(10), 04015001.

[15] Nematollahi, B., Sanjayan, J., and Shaikh, F.U.A. (2016). "Matrix design of strain hardening fiber reinforced engineered geopolymer composite". Composites Part B: Engineering, 89, 253-265.

[16] Nematollahi, B., Ranade, R., Sanjayan, J., and Ramakrishnan, S. (2017). "Thermal and Mechanical Properties of Sustainable Lightweight Strain Hardening Geopolymer Composites". Achieves of Civil and Mechanical Engineering, 17, 55-64.

[17] Nematollahi, B., Sanjayan, J., Qui, J., and Yang, E.H. (2016). "Micromechanics-based investigation of a sustainable ambient temperature cured one-part strain hardening geopolymer composite". Construction and Building Materials, Submitted for publication.

[18] Nematollahi, B., Sanjayan, J., and Shaikh, F.U.A. (2015). "Synthesis of heat and ambient cured one-part geopolymer mixes with different grades of sodium silicate". Ceramics International, 41(4), 5696-5704.

[19] Yang, E.H., Yang, Y., and Li, V.C. (2007). "Use of High Volumes of Fly Ash to Improve ECC Mechanical Properties and Material Greenness". ACI Materials Journal, 104(6).

[20] Hardjito, D., Wallah, S.E., Sumajouw, D.M., and Rangan, B.V. (2014). "On the development of fly ash-based geopolymer concrete". ACI Materials Journal. 101(6), 467-72. [21] Nematollahi, B., and Sanjayan, J. (2014). "Effect of different superplasticizers and activator combinations on workability and strength of fly ash based geopolymer". Materials \& Design, 57, 667-672.

[22] ASTM C109/C109M, Standard test method for compressive strength of hydraulic cement mortars (using $50 \mathrm{~mm}$ [2 in.] cube specimens). (2007). United States: ASTM Standards.

[23] Karihaloo, B., and Nallathambi, P. (1990). "Effective crack model for the determination of fracture toughness $\left(\mathrm{K}_{\mathrm{IC}}{ }^{\mathrm{e}}\right)$ of concrete". Engineering Fracture Mechanics, 35(4), 637-645.

[24] Redon, C., Li, V. C., Wu, C., Hoshiro, H., Saito, T., and Ogawa, A. (2001). "Measuring and modifying interface properties of PVA fibers in ECC matrix". ASCE Journal of Materials in Civil Engineering, 13(6), 399-406.

[25] Li, V.C., and Mishra, D.K. (1992). "Micromechanics of fiber effect on the uniaxial compressive strength of cementitious composites", in Fiber Reinforced Cement and Concrete, Proceedings of the 4th RILEM International Symposium, Sheffield, U.K., edited by R. N. Swamy, pp. 400-414.

[26] ACI 213R; ACI Committee 231. Guide for structural lightweight-aggregate concrete. (2014). United States: ACI Standards.

[27] Petersson P. (1980). "Fracture energy of concrete: Method of determination". Cement and Concrete Research, 10(1), 79-89.

[28] Golewski, G.L. and Sadowski, T. (2014). "An analysis of shear fracture toughness $\mathrm{K}_{\text {IIc }}$ and microstructure in concretes containing fly-ash". Construction and Building Materials, 51, 207-214. 
[29] Pan, Z., Sanjayan, J.G., and Rangan, B.V. (2011). "Fracture properties of geopolymer paste and concrete". Magazine of Concrete research, 63(10), 763-771.

[30] Li, V., Mishra, D. and Wu, H.-C. (1995). "Matrix design for pseudo-strain-hardening fiber reinforced cementitious composites". Materials and Structures, 28, 586-595.

[31] Lange, D.A., Jennings, H.M., and Shah, S.P. (1993). "Relationship between fracture surface roughness and fracture behavior of cement paste and mortar". Journal of the American Ceramic Society, 76(3), 589-597.

[32] Kanda, T., and Li, V. C. (1998). "Interface property and apparent strength of highstrength hydrophilic fiber in cement matrix". ASCE Journal of Materials in Civil Engineering, 10(1), 5-13.

[33] Li, V.C., Wang, S., and Wu, C. (2001). "Tensile strain-hardening behavior of polyvinyl alcohol engineered cementitious composite (PVA-ECC)". ACI Materials Journal, 98(6).

[34] Kanda, T., and Li, V.C. (2006). "Practical design criteria for saturated pseudo strain hardening behavior in ECC". Journal of advanced concrete technology, 4(1), 59-72.

[35] Yang, E.H., and Li, V.C. (2010). "Strain-hardening fiber cement optimization and component tailoring by means of a micromechanical model". Construction and building Materials, 24(2), 130-139.

[36] Yang, E.-H., Wang, S., Yang, Y., and Li, V. C. (2008). "Fiber-bridging constitutive law of engineered cementitious composites". Journal of advanced concrete technology, 6(1), 181193.

[37] Yang, E.H., and Li, V.C. (2014). "Strain-rate effects on the tensile behavior of strainhardening cementitious composites". Construction and Building Materials, 52, 96-104. 


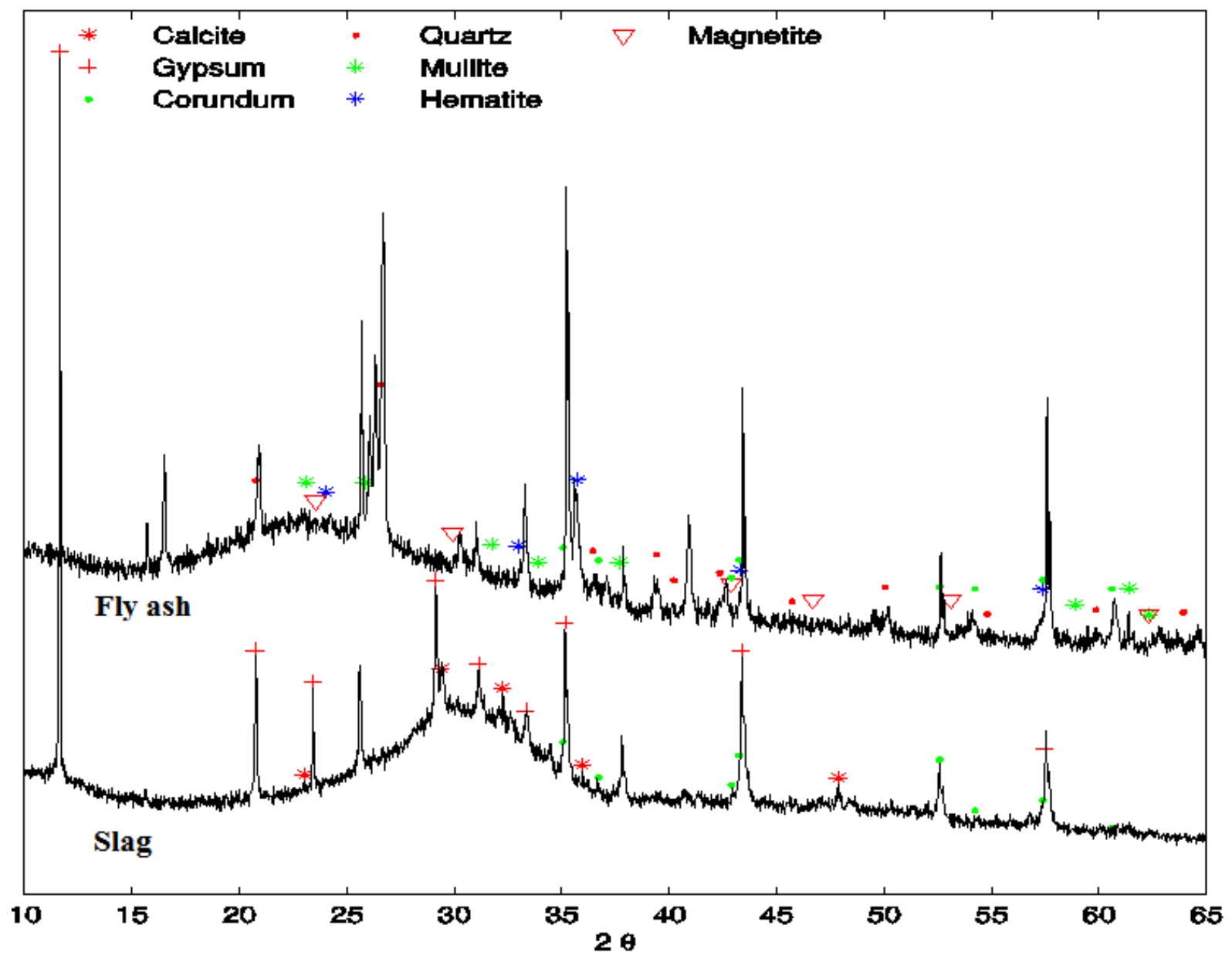

Figure 1: XRD patterns of the fly ash and slag 


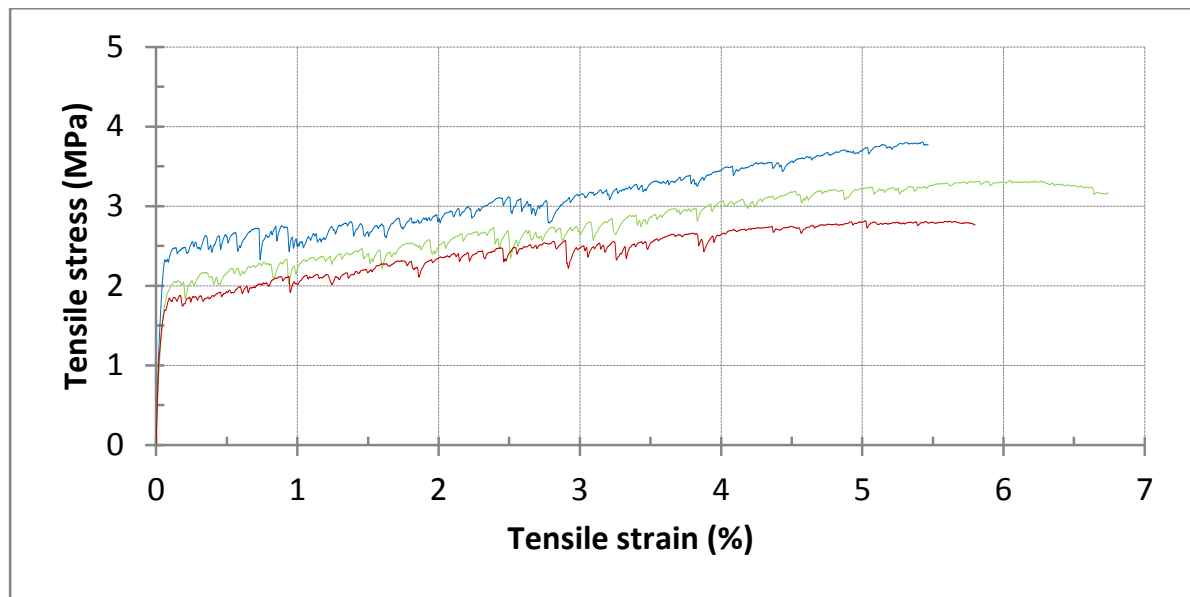

Figure 2: Tensile stress-strain responses of heat cured one-part PE-SHGC-H 


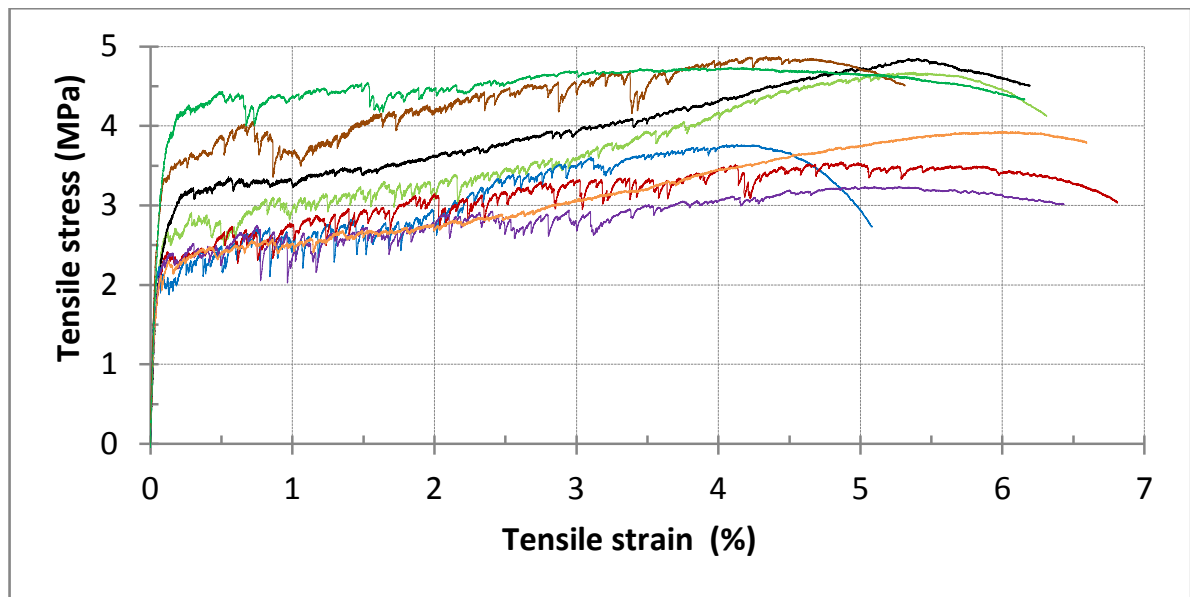

Figure 3: Tensile stress-strain responses of ambient cured one-part PE-SHGC-A 


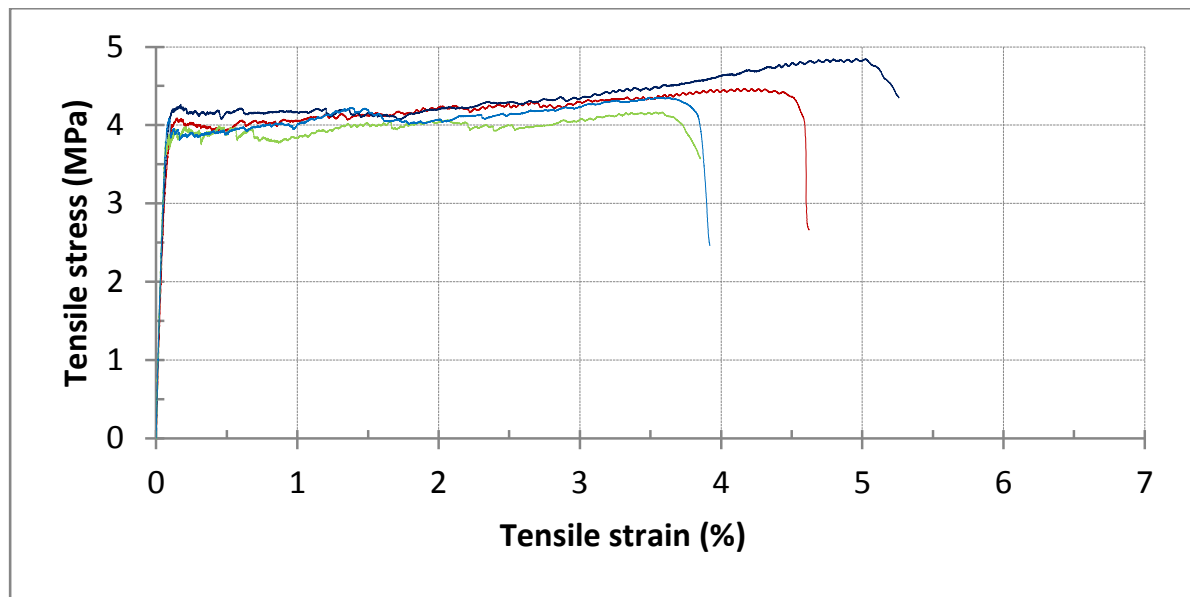

Figure 4: Tensile stress-strain responses of ambient cured one-part PVA-SHGC-A 


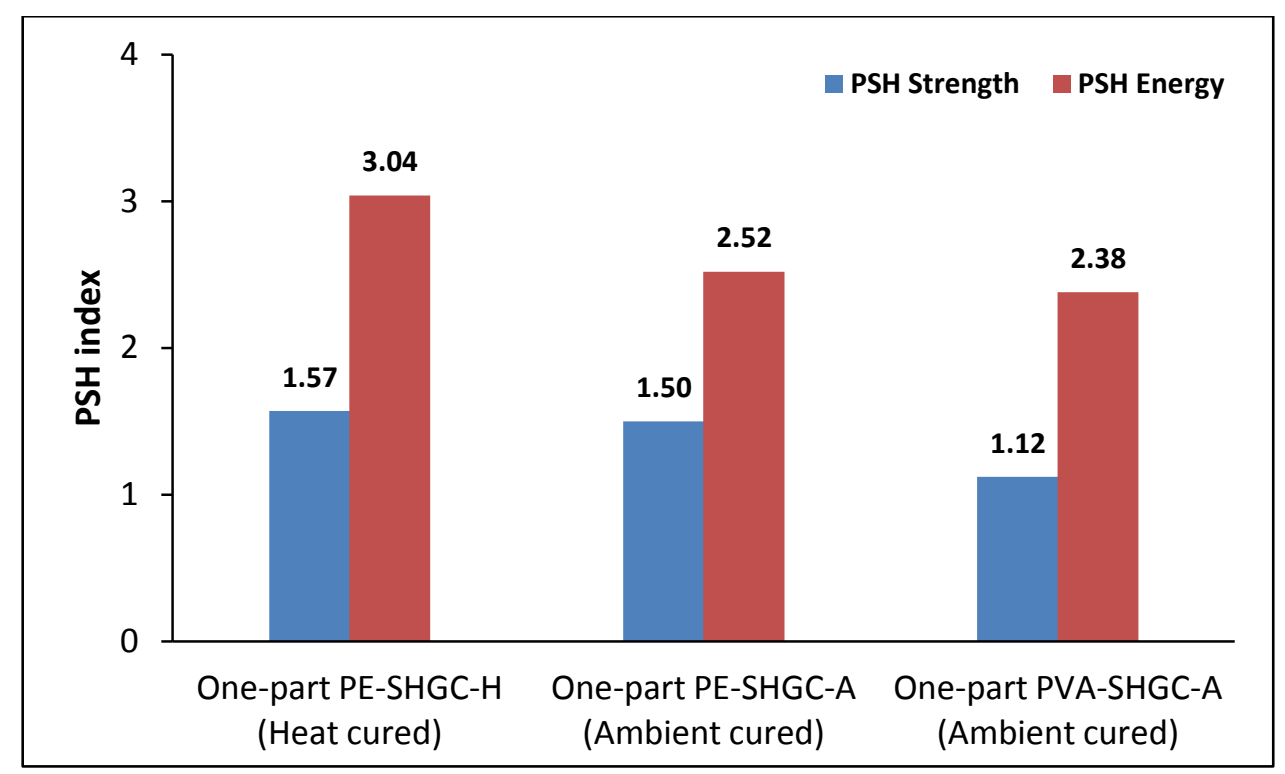

Figure 5: PSH indices of the developed one-part SHGCs 


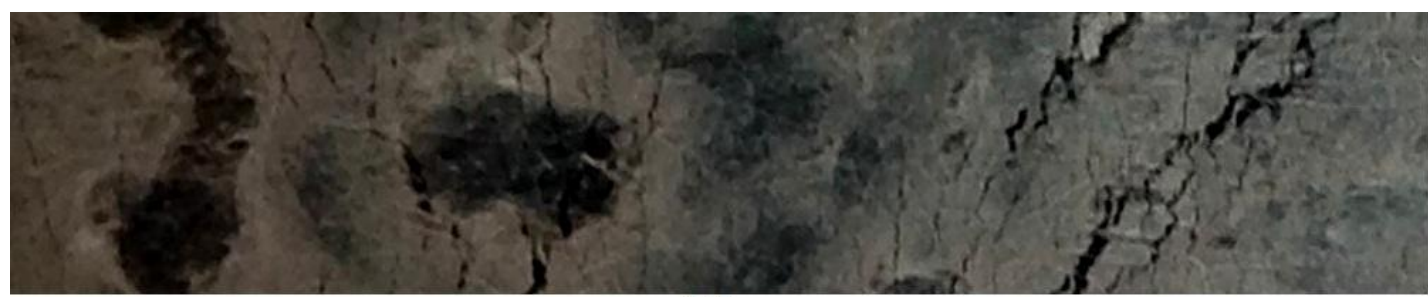

(a)

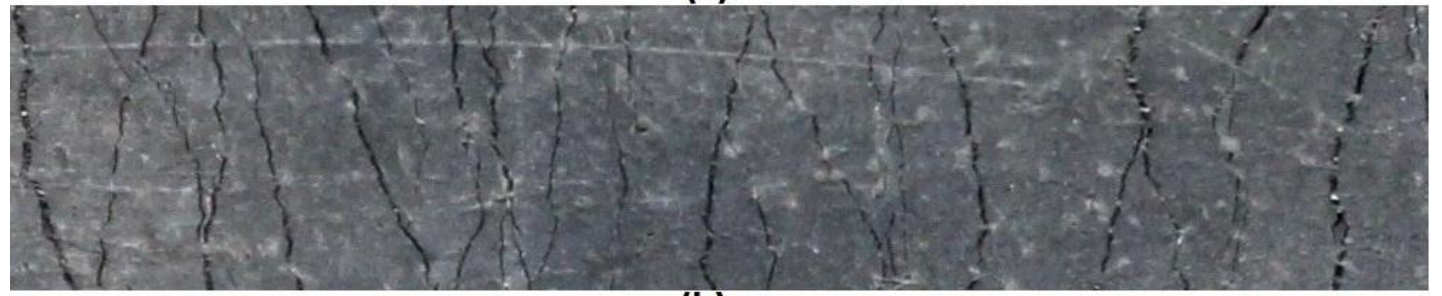

(b)

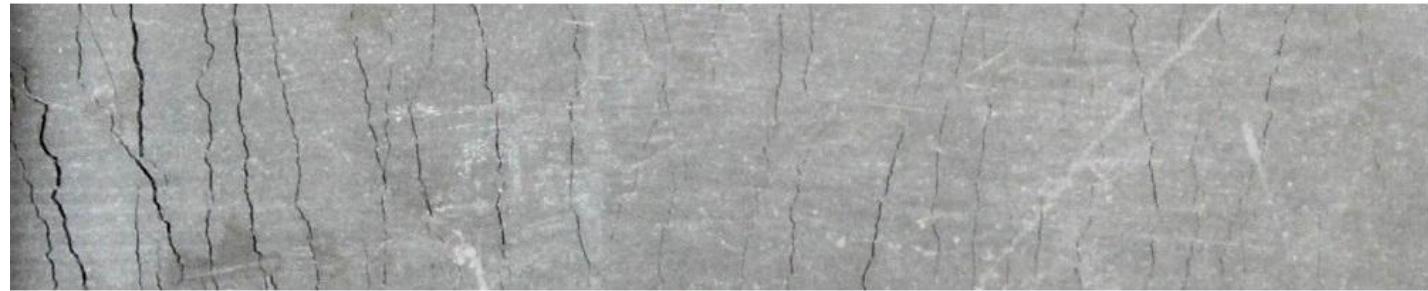

(c)

Figure 6: Typical multiple cracking pattern of (a) ambient cured one-part PE-SHGC-A, (b) heat cured one-part PE-SHGC-H, and (c) ambient cured one-part PVA-SHGC-A 
Table 1: Mix proportion of one-part "dry mix" SHGCs

\begin{tabular}{|c|c|c|c|c|c|c|c|}
\hline \multirow{2}{*}{ Mix ID } & \multicolumn{3}{|c|}{$\begin{array}{l}\text { One-part "dry mix" } \\
\text { geopolymer binder }\end{array}$} & \multirow{2}{*}{ Water $^{2}$} & \multirow{2}{*}{$\begin{array}{l}\text { PVA } \\
\text { fiber }\end{array}$} & \multirow{2}{*}{$\begin{array}{l}\text { PE } \\
\text { fiber }\end{array}$} & \multirow{2}{*}{$\begin{array}{l}\text { Curing } \\
\text { condition }\end{array}$} \\
\hline & $\begin{array}{l}\text { Fly } \\
\text { ash }\end{array}$ & Slag & $\begin{array}{c}\text { Solid } \\
\text { activator }\end{array}$ & & & & \\
\hline $\begin{array}{c}\text { One-part } \\
\text { PE-SHGC-H }\end{array}$ & 0.50 & 0.50 & 0.08 & 0.35 & --- & 0.02 & $\begin{array}{l}\text { Heat } \\
\text { curing }\end{array}$ \\
\hline $\begin{array}{c}\text { One-part } \\
\text { PE-SHGC-A }\end{array}$ & 0.50 & 0.50 & 0.08 & 0.35 & --- & 0.02 & $\begin{array}{l}\text { Ambient } \\
\text { curing }\end{array}$ \\
\hline $\begin{array}{c}\text { One-part } \\
\text { PVA-SHGC-A }\end{array}$ & 0.50 & 0.50 & 0.08 & 0.35 & 0.02 & --- & $\begin{array}{l}\text { Ambient } \\
\text { curing }\end{array}$ \\
\hline
\end{tabular}

Note: All numbers are mass ratios of the precursor weight (fly ash + slag) except fiber content (volume fraction).

${ }^{1}$ Composed of anhydrous sodium metasilicate powder.

2 Added to the one-part "dry mix" geopolymer binder. 
Table 2: Chemical composition of the fly ash and slag

\begin{tabular}{|l|c|c|}
\hline \multirow{2}{*}{ Chemical } & \multicolumn{2}{|c|}{ Component (wt. \%) } \\
\cline { 2 - 3 } & Fly ash & Slag \\
\hline $\mathrm{Al}_{2} \mathrm{O}_{3}$ & 25.56 & 12.37 \\
\hline $\mathrm{SiO}_{2}$ & 51.11 & 32.76 \\
\hline $\mathrm{CaO}$ & 4.3 & 44.64 \\
\hline $\mathrm{Fe}_{2} \mathrm{O}_{3}$ & 12.48 & 0.54 \\
\hline $\mathrm{K}_{2} \mathrm{O}$ & 0.7 & 0.33 \\
\hline $\mathrm{MgO}$ & 1.45 & 5.15 \\
\hline $\mathrm{Na}_{2} \mathrm{O}$ & 0.77 & 0.22 \\
\hline $\mathrm{P}_{2} \mathrm{O}_{5}$ & 0.885 & 0.014 \\
\hline $\mathrm{TiO}_{2}$ & 1.32 & 0.51 \\
\hline $\mathrm{MnO}$ & 0.15 & 0.37 \\
\hline $\mathrm{SO}_{3}$ & 0.24 & 4.26 \\
\hline $\mathrm{LOI}^{1}$ & 0.57 & 0.09 \\
\hline
\end{tabular}

${ }^{1}$ Loss on ignition 
Table 3: Properties of the PVA and PE fibers

\begin{tabular}{|c|c|c|c|c|c|c|}
\hline Fiber type & $\begin{array}{c}\text { Diameter } \\
(\boldsymbol{\mu m})\end{array}$ & $\begin{array}{c}\text { Length } \\
(\mathbf{m m})\end{array}$ & $\begin{array}{c}\text { Young's } \\
\mathbf{m o d u l u s} \\
(\mathbf{G P a})\end{array}$ & $\begin{array}{c}\text { Elongation } \\
(\mathbf{\%})\end{array}$ & $\begin{array}{c}\text { Density } \\
\left(\mathbf{g} / \mathbf{c m}^{\mathbf{3}}\right)\end{array}$ & $\begin{array}{c}\text { Nominal } \\
\mathbf{S t r e n g t h} \\
(\mathbf{M P a})\end{array}$ \\
\hline PVA-RECS 15 & 40 & 8 & 41 & 6 & 1.3 & 1600 \\
\hline PE-SK71 & 12 & 12 & 123 & $3-5$ & 0.97 & 3500 \\
\hline
\end{tabular}


Table 4: Workability, density and compressive strength results

\begin{tabular}{|c|c|c|c|c|c|}
\hline \multirow[t]{2}{*}{ Mix ID } & \multirow[t]{2}{*}{$\begin{array}{c}\text { Matrix } \\
\text { workability }^{1}\end{array}$} & \multicolumn{2}{|c|}{$\begin{array}{l}\text { Density; } \\
\left(\mathrm{kg} / \mathbf{m}^{3}\right)\end{array}$} & \multicolumn{2}{|c|}{$\begin{array}{c}\text { Compressive } \\
\text { strength; }(\mathrm{MPa})^{2}\end{array}$} \\
\hline & & Matrix & Composite & Matrix & Composite \\
\hline One-part PE-SHGC-H & \multirow{3}{*}{3.52} & 1880 & 1837 & $44.7 \pm 4.1$ & $33.9 \pm 3.7$ \\
\hline One-part PE-SHGC-A & & 1895 & 1844 & $48.6 \pm 4.1$ & $44.3 \pm 2.2$ \\
\hline One-part PVA-SHGC-A & & 1895 & 1849 & $48.6 \pm 4.1$ & $48.7 \pm 4.1$ \\
\hline
\end{tabular}

${ }^{1}$ In terms of relative slump value of the fresh matrix.

${ }^{2}$ The numbers indicate Average \pm Standard Deviation. 
Table 5: Matrix fracture test results

\begin{tabular}{|c|c|c|c|}
\hline Mix ID & $\begin{array}{c}\text { Matrix elastic } \\
\text { modulus a }^{\text {a }} \\
\mathbf{E}_{\mathbf{m}} ;(\mathbf{G P a})\end{array}$ & $\begin{array}{c}\text { Matrix fracture } \\
\text { toughness }{ }^{\mathrm{a}}, \\
\left.\mathrm{K}_{\mathrm{m}} ;\left(\mathrm{MPa}^{1 / 2}\right)^{1 / 2}\right)\end{array}$ & $\begin{array}{c}\text { Crack tip } \\
\text { toughness }{ }^{\mathrm{b}}, J_{t i p} ; \\
\left(\mathrm{J} / \mathrm{m}^{2}\right)\end{array}$ \\
\hline $\begin{array}{l}\text { Heat cured one-part } \\
\text { SHGC matrix }\end{array}$ & $4.8 \pm 0.25^{c}$ & $0.287 \pm 0.0127^{\mathrm{c}}$ & 17.2 \\
\hline $\begin{array}{l}\text { Ambient cured one-part } \\
\text { SHGC matrix }\end{array}$ & $5.3 \pm 0.29^{c}$ & $0.316 \pm 0.0136^{c}$ & 18.8 \\
\hline
\end{tabular}

${ }^{\mathrm{a}}$ Following ECM [23].

${ }^{\mathrm{b}}$ Following Eq. (1) [30].

${ }^{\mathrm{c}}$ The numbers indicate Average \pm Standard Deviation. 
Table 6: Fiber-matrix interface properties

\begin{tabular}{|c|c|c|c|}
\hline Mix ID & $\begin{array}{c}\text { Chemical } \\
\text { bond strength, } \\
\mathbf{G}_{\mathbf{d}} ;\left(\mathbf{J} / \mathbf{m}^{2}\right)\end{array}$ & $\begin{array}{c}\text { Frictional } \\
\text { bond strength, } \\
\tau_{0} ;(\mathrm{MPa})\end{array}$ & $\begin{array}{c}\text { Slip hardening } \\
\text { coefficient, } \beta\end{array}$ \\
\hline One-part PE-SHGC-H & --- & $1.32 \pm 0.49$ & $0.014 \pm 0.0013$ \\
\hline One-part PE-SHGC-A & --- & $1.36 \pm 0.40$ & $0.019 \pm 0.0015$ \\
\hline One-part PVA-SHGC-A & $1.03 \pm 0.34$ & $2.14 \pm 0.62$ & $0.041 \pm 0.0070$ \\
\hline
\end{tabular}

Note: The numbers indicate Average \pm Standard Deviation. 
Table 7: Uniaxial tension test results

\begin{tabular}{|c|c|c|c|}
\hline Mix ID & $\begin{array}{c}\text { first-crack } \\
\text { strength, } \boldsymbol{\sigma}_{\boldsymbol{f} \boldsymbol{c}} ; \\
(\mathbf{M P a})\end{array}$ & $\begin{array}{c}\text { Ultimate tensile } \\
\text { strength, } \boldsymbol{\sigma}_{\boldsymbol{c u}} ; \\
\mathbf{( M P a )}\end{array}$ & $\begin{array}{c}\text { Tensile strain } \\
\text { capacity } \boldsymbol{\varepsilon}_{\boldsymbol{c} \boldsymbol{u}} ; \\
(\boldsymbol{\%})\end{array}$ \\
\hline One-part PE-SHGC-H & $2.1 \pm 0.24$ & $3.3 \pm 0.50$ & $5.5 \pm 0.52$ \\
\hline One-part PE-SHGC-A & $2.8 \pm 0.66$ & $4.2 \pm 0.66$ & $4.9 \pm 0.68$ \\
\hline One-part PVA-SHGC-A & $4.1 \pm 0.095$ & $4.6 \pm 0.26$ & $4.2 \pm 0.71$ \\
\hline
\end{tabular}

Note: The numbers indicate Average \pm Standard Deviation. 